\title{
What do University Students Expect from the Future?
}

\author{
Natalia N. Meshcheryakova \\ Natalia A. Lukianova \\ Tomsk Polytechnic University, Russian Federation \\ Corresponding Email: Natalia.tib@mail.ru
}

Doi:10.5901/mjss.2015.v6n6s7p206

\section{Abstract}

\begin{abstract}
The article describes the results of sociological research "Vision of the future in the ideas of University students", which was carried out in National Research Tomsk Polytechnic University within implementation of international project "Interdisciplinary Research of the Future". It was an exploring-type of research, based on qualitative methods. Semantic analysis has been carried out for interpretation of the obtained data. The results allowed defining the main concepts, via which University students create the vision of their personal future, shape its hierarchy and identify emotional and rational components of these concepts. Besides, the developed methodology of the research allows comparing the vision of the future, which is created from unconscious paradigms and the one, which exists at the level of consciousness and is more subjected to the pressure of the social stereotypes. Also the difference in vision of the future was traced depending on the gender of the respondents. We assume that the obtained results will facilitate the promotion of academic research related to the content of academic programs of higher professional education.
\end{abstract}

Keywords: future vision, semiotics, qualitative research, post-materialistic values

\section{Introduction}

UNESCO manages the policy of the international community in the field of education and its overriding priorities are providing for opportunity to get tuition-free basic education by all and achieve gender equality. These are the objectives that have been introduced in program "Education for all", results of which will be announced in the current year of 2015. However, in the report of UNESCO of 2011 it was announced that they will not be achieved.

In view of un-resolution of such fundamental issues, the necessity of revision of the academic programs stated by us could be assumed premature. Not in the sense of updating educational technologies or academic programs, but through the prism of the idea to what future it prepares its students and whether this idea matches with the same vision of the future that is born in the minds of the youth. We wanted to initiate a discussion on advance vision of the development of educational environment.

In National Research Tomsk Polytechnic University international network project "Interdisciplinary Research of the Future" ${ }^{1}$ (T.I.P.F.) is being implemented. Our objective is to develop mechanisms and instruments for planning and foreseeing the future, including the development of new educational technologies. This is a multilateral project, one of intermediate results of which is to be shown in our article.

The vision of the future is inseparable from its bearer, from understanding of the generation, which in the future two decades shall determine development strategies of social systems, set objectives and choose ways for their achievement. Thus in the framework of our project the applied research "Vision of the future in the ideas of University students" was initiated and implemented in April 2014. We wanted to show not only its results, but our own vision of how it could add value to the discussion on contemporary international trends in the development of education and academic studies.

\section{Literature Review}

The most thorough researches of young people as an object of socialization and self-realization, of its role in the social

${ }^{1}$ Tomsk international project "Interdisciplinary Research of the Future". Web-site of NR TPU. Electronic resource. Tomsk, 2014. URL: http://tpu.ru/today/tpu-structure/instituty-fakultety-kafedry/isht/soc/international/ 
structure reproduction were conducting by the Institute of Sociology of the Russian Academy of Sciences under the leadership of M.K. Gorshkov and F.E. Sheregi from 1998 to 2009 (2010). Special attention was paid to the formation of young people mass consciousness, the reasons for their low civic engagement, their ethnic and religious tolerance. A particular chapter of their study is devoted to the study of young people motivation career choices, the problem of employment of professional educational institutions graduates.

The researchers use quantitative analysis methods life goals and values of youth. The study concludes that there is not a conscious model of the future in Russia (Gorshkov \& Sheregi, 2010). The social structure of a modern Russian society forms the youth entitlement mentality, self-distrust, inability to survive amid competition at labor. These trends pose serious challenges for professional orientation of youth. In conclusion, the authors reveal that a change of the conservative social structure and conservative mentality requires intensification of the contradictions between the generations up to the conflict (Gorshkov \& Sheregi, 2010).

Lebedeva (2009) presented the results of the studies youth system of values by the Shalom Schwartz methodology (1 $1^{\text {st }}$ wave: $1999,2^{\text {nd }}$ wave: $2005 \& 3^{\text {rd }}$ wave: 2009 ). The respondents were students of Russian universities. Their results were compared with the similar results of students from Eastern and Western Europe. If at the beginning of research, students of Eastern Europe possessed less skill, intellectual and affective autonomy than their peers from Western Europe, and the Russians have this gap was particularly noticeable. In the following waves Russian students surpassed in skill and intellectual autonomy not only their peers from the East, but from the Western Europe too. In 2005, the Russians have been marked by a simultaneous increase in the values of conservatism (maintaining social order, respect for traditions, protection of the family, self-discipline) and equality (equality, social justice, freedom, responsibility, honesty). And in 2009 the value of craftsmanship and intellectual autonomy have become the most significant in relation to other (Lebedeva, 2009, p. 63-64). Consequently, the attitude of young people to future is changing as compared to the older generation installations.

\section{Research Methodology}

It was an exploring-type of research, aimed at development and testing of methodological tools for studying the concept of "personal future" of University students. The specific feature of the research is the involvement of the group of respondents, participating in the written survey, students of Tomsk Polytechnic University, to analysis and interpretation of the obtained results. We tackled the task of semantic analysis (Halliday, 1978; Hodge \& Kress 1988; Randviir, 2004), markers of the future in students' interpretation, functions of words, which they use, their relation to each other and surrounding environment.

Besides, the objectives of the research were to:

1. Establish whether young people today make long-term life plans.

2. Find out the definition of "personal future" for University students.

3. Develop and test methodological tools.

The subject of the research was the subjectively significant ideas of University students on personal future. Written survey, divided into two stages based on one and the same non-formalized questionnaire was used.

At the first stage, respondents were questioned without preliminary explanation of the objective of the research, in "time pressure" mode (4 minutes). The set objective was to identify unconscious ideas of respondents about the future. Regarding personal data the researchers were interested only in gender, since full-time students were very uniform both by age and social level. There were two substantial questions:

First: Do you think about long-term personal future, 10 years ahead and more?

1) Yes, I make long-term life plans

2) Yes, it happens, generally, nothing certain

3) No, one should live here and now

4) No, future scares me

Second: Write down three words, which describe the vision of your future.

The second stage of the written survey was held a week after the first one with the same group of respondents. The students were informed in advance about the objectives of the research and they were given time to think it over. The objective was the following: to identify conscientious ideas of the student youth about the future, stereotypes of social conscience in their personal understanding.

Used methods of analysis were quantitative (Babbie 2008; Firebaugh 2008) and predominantly qualitative (Becker 1990; Denzin \& Lincoln 2011; Gubrium 2009; Franklin 2012). Respondents were involved in the analysis of the obtained results (not disclosing personal data) for clarifying the notions of markers of the future. This allowed interpreting the 
obtained results taking into consideration the meanings implied by the youth.

\section{Analysis \& Findings}

The first question of the questionnaire was whether students think about their long-term future. Out of significant results one should note the absence of such an answer during the first and second survey as: "No, future scares me", which means a general optimistic attitude in the medium. And also a small percentage of answers, such as: "No, one should live here and now" (7\% at the first stage and $8.5 \%$ at the second). But ideas of respondents about the future are mainly tentative. The most frequent answer is "Yes, it happens, generally, nothing clear" ( $86 \%$ and $58 \%)^{2}$. There is a significant difference in results of the first and second survey. The percentage of those, who make long-term life plans increased from $7 \%$ to $33.5 \%$. Time given for thinking has played its role. Clearness of planning of the future both during the first and second survey is more typical for young men than for young ladies.

For the second question each respondent both during the first attempt, spontaneously, and during the second after thinking it over stated three notions, most significant for the vision of the personal future.

Obtained data have been analyzed and interpreted in three stages:

First stage: Definition of concepts (sense-groups): "Future is...". After systematization of all speech markers, the most significant concepts for respondents are:

"Family" F. Speech markers: family, house, marriage, children, husband, father.

"Carrier" C. Speech markers: carrier, work, favorite job, success, business.

"Travelling/movements" T. Speech markers; travelling, movement to another city, tourist.

"Material wealth" MW. Speech markers: welfare, high salary, money.

"Self-development" SD. Speech markers; self-development, elaboration, creation, creativity, perspective.

"Emotional well-being" EW. Speech markers: love, nirvana, sea (ocean), warm weather, freedom, happiness.

Single speech markers, such as health, friendship of peoples have not been included in any concept. Certain markers were attributed to concepts related to the rest two markers stated by a particular respondent. For example, marker "success" was attributed to Carrier since it was stated in a triangle of markers carrier-success-family (sequence of replies is preserved).

Concepts have been prioritized in conformity with the frequency of their appearance in replies of respondents:

Table 1. Concepts used in the analysis

\begin{tabular}{llcccccc}
\hline & \multirow{2}{*}{ Concepts } & \multicolumn{3}{c}{ First survey, \% } & \multicolumn{3}{c}{ Second survey, \% } \\
\cline { 3 - 7 } 1 & Family "F" * & total & male & female & total & male & female \\
\cline { 2 - 7 } 2 & Carrier "C" & 50.28 & $40^{* *}$ & 77.78 & 83.33 & 75 & 87.5 \\
3 & Travelling "T" & 20 & 66.66 & 41.67 & 50 & 37.5 \\
4 & Emotional well-being "EW" & 35.71 & 20 & 44.44 & 50 & 50 & 50 \\
5 & Material wealth "MW" & 35.71 & 60 & 22.22 & 16.67 & 25 & 12.5 \\
6 & Self-development "SD" & 14.29 & 20 & 11.11 & 16.67 & 25 & 12.5 \\
\hline
\end{tabular}

*Hereinafter referred to: percentage of respondents, who have selected this speech marker of this concept at least one time.

${ }^{*}$ Hereinafter referred to as: from the number of participants of their gender.

Besides, two couples of dual indicators, on the basis of which obtained results were analyzed, have been selected:

1) Rational vision of the future $\mathbf{R}$ / Emotional vision of the future $\mathbf{E}$

2) Orientation to result RS / Orientation to process PR

The first dual couple can be the sign of the rational type of personality (all three notions re-create rational vision of the future), emotional type of personality (all three notions re-create emotional vision of the future), and intermediate types: rational-emotional (2 replies $\mathbf{R}$, one $\mathbf{E}$ ) and emotional-rational (2 replies $\mathbf{E}$, one $\mathbf{R}$ )

\footnotetext{
${ }^{2}$ Herein after referred to: the first figure is percentage of answers to the question during the first survey, second - during the second, except for specifically described cases.
} 
Table 2. Results of identification of personality types by criterion rational/emotional

\begin{tabular}{lccccccc}
\hline Identification of personality types by criterion Rational/emotional & \multicolumn{3}{c}{ First survey, \% } & \multicolumn{3}{c}{ Second survey, \% } \\
\cline { 2 - 7 } & total & male & female & total & male & female \\
\hline Rational type of personality "R" & 28.57 & 20 & 33.33 & 41.67 & 50 & 37.5 \\
2 Emotional type of personality "E" & 14.29 & 40 & 0 & 16.67 & 20 & 12.5 \\
3 Rational-emotional type of personality "RE" & 57.14 & 40 & 66.67 & 41.67 & 20 & 50 \\
4 Emotional-rational type of personality "ER" & 0 & 0 & 0 & 0 & 0 & 0 \\
\hline
\end{tabular}

The second dual couple shows the vision of the future as a result, final product or in the notions of process, development:

Table 3. Results of presentation of the future oriented towards the result/ oriented towards the process

\begin{tabular}{lllccccc}
\hline & Vision of the future oriented towards the result// & \multicolumn{3}{c}{ First survey, \% } & \multicolumn{3}{c}{ Second survey, \% } \\
\cline { 2 - 8 } & oriented towards the process & total & male & female & total & male & female \\
\cline { 2 - 8 } 1 & Orientation to the result "RS" & 7.14 & 20 & 0 & 33.33 & 50 & 25 \\
2 & Orientation to the process "PR" & 21.43 & 60 & 0 & 16.67 & 25 & 12.5 \\
3 & "RS-PR" & 42.86 & 20 & 55.56 & 41.67 & 0 & 62.5 \\
4 & "PR-RS" & 28.57 & 0 & 44.44 & 8.33 & 25 & 0 \\
\hline
\end{tabular}

Second stage: At the second stage relations between concepts have been established. The most significant concept in the vision of the future of respondents is "Family". At the same time their attitude to the issue of creating a family is rational and they focus on the certain final result. Only two respondents and only in the first survey have attributed speech marker "love" to "family". More frequently family is related to such definitions as "house", "wedding", and "marriage", "children". As many other results of this survey complete vanishing of marker "love" during the second survey is impossible for interpretation without taking into account two discovered tendencies in creation of the vision of the future by the respondents:

The vision of the future is created rather rationally than emotionally: during the first survey $85.71 \%$ of respondents had mainly rational vision $(\mathbf{R}+\mathbf{R E})$, during the second survey $-83.34 \%$. At that it does not matter whether it has been done at unconscious level or at the level of consciousness, rational element prevails over emotional.

The vision of the desired future is more oriented towards the result than the process. If during the first survey ratio is $50 / 50$, then in the second - orientation towards result is $75 \%$. Our society is used to estimate their achievements by the specific result, which was observed at the second stage of the survey, when respondents had time to think.

The second most-widely used concept is "Carrier", but only during the first survey. During the second survey this concept is shifted from the second place by "Travelling". During the first survey three of these concepts (family-carriertravelling) plus material wealth together with family or carrier are enough for $50 \%$ of respondents, during the second $66.67 \%$. This growth is directly related to the increased number of answers oriented towards the final result. In the course of determination of the vision of the future priorities are directly related to age of the respondents (20-21 years). Thus, concept "Health" is not present in replies at all (one reference during the second survey), whereas the opportunity to travel, especially during the second survey is considered a value. During analysis of semantics of the speech markers, the question, what is closer to the definition of "travelling" 1) freedom to move 2) a desire to see the world - respondents chose the second variant.

The fourth important concept is "Emotional well-being". During the first survey its markers were selected by slightly more than one third of respondents, however, during the second survey the share of those, who have chosen the same has dropped twice. It is probably explained by the fact that after consideration the tendency to see the future as a set of results but not as ongoing processes has increased, while speech markers of emotional well-being: love, nirvana, freedom, happiness describe future as emotionally favorable process.

Of particular notice, despite widely spread stereotype, the emotional vision of the future, especially during the first survey, when unconscious ideas have been more revealed, tend to be chosen more frequently by young men than young women: $60 \%$ and $22 \%$ correspondingly. During the second survey when stereotypes of the public consciousness started to be more revealed, young men displace orientation towards achievement of the emotional well-being by the rational approach. Concept "Carrier" clearly shows that public stereotypes influence more during the second survey. During the first survey speech markers of this concept were typical for $20 \%$ of young men and $67 \%$ of young women, but during the second $-50 \%$ of male respondents and $35.7 \%$ of female. Carrier as male domain is one of the stereotypes of the collective consciousness of Russia. But indeed young women show greater strive for achievements at the unconscious 
level, but they suppress this idea by their consciousness. Probably these results can be interpreted as changes of gender roles in the contemporary society.

Concepts "Material well-being" and "Self-development" have equal small percentage. If you try to estimate this phenomenon with the help of concept of post-materialistic values of R. Inglehart (Inglehart \& Welzel, 2005), then these results demonstrate absolutely different tendencies. On the one hand, generation, grown up in the conditions of economic and personal security shall not give priority to wealth, money, which is demonstrated by our respondents. On the other hand, the same generation shall be oriented towards self-development and quality of life. Speech markers, confirming the orientation towards self-development (self-development, elaboration, creation, creativity, perspective) in our survey are occasional and represented by the same respondents. But, hypothetically this can be related to the same rational orientation towards final, measured product. A special survey is required to prove the same.

Third stage. Interpretation of the obtained results. Conclusions.

The vision of the future of University students identified as a result of qualitative research, carried out with the group of TPU students cannot claim to be representative of its results, but provides for some tendencies of the vision of the future of University students.

Firstly, the vision of the future is not causing anxiety in young people. That is not to say that young people (in this case students) live by one day, they formulate and keep in their mind the vision of the desired future, to which they strive for.

Secondly, the vision of the future depends on the age of respondents: diminishing significance of concept "Health", mainstreaming concept "Travelling" in the meaning of "to see the world".

Thirdly, rational approach and tendency to show it in terms of the achieved result but not ongoing processes predominate in the vision of the future, which together with relative share of "Carrier" concept shows great strive of young people for the so called "achievement", which is typical for contemporary social groups. The predominance of concepts family - carrier - travelling makes life objectives of students socially adoptive and stabilizes the system to a high extent.

Fourthly, the vision of the future shows great orientation of young people towards family in traditional understanding of this social institute.

Fifthly, as both stages of survey have implied, the second survey showed the vision of the future through the prism of public stereotypes more than the first.

Sixthly, despite existing stereotypes related to gender, these were the young men, who have shown a more subjective significance of emotional comfort than young women and young women have been more prone to unconscious idea of "achievement", which can prove a gradual change of gender roles in the society under the same strong pressure of traditional stereotypes related to gender.

\section{Conclusion}

Since this research was of exploring-type, verification of the obtained results is possible during carrying out of the same surveys with additional groups of respondents. Results obtained after carrying out surveys among University students in other societies with further comparison of results can be most interesting.

On the Second World Conference on Higher Education carried out by UNESCO in 2009 when preparing final communiqué a dispute was provoked whether to consider education as a public good and a matter of responsibility of states of all countries (Maldonado \& Verger, 2010). The initial variant: "Higher education plays an important role in nationbuilding. Higher education as a public good shall become the matter of responsibility of many countries" was rejected for the sake of neutral "Higher education as a public good and strategic imperative for all levels of education and the basis for scientific survey, innovations and creativity shall become the matter of responsibility and economic support of states of all countries". Yet higher education shall not be considered only the way for the society to prepare highly professional staff for the economy, or a lift of social mobility for a separate individual. Thus, as researchers note communiqué worked out on the conference has such fragmentary nature (Maldonado- Maldonado \& Verger, 2010) and does not flow a clear and consistent message to the international academic society, which shows misunderstanding of its role in the development of trends of social systems. Our research has shown that on the whole students are oriented towards vision of the desired future, which as attractor sets the parameters of order related to stability, balance. But we know that due to May events of 1968 in France, students' unrest in contemporary Greece etc. the same medium can become the source of destabilization of the system. Academic research aimed at determination of the role of higher education in contemporary society, expectations of the student youth related to their future and future of the whole society can help working out more distinct and substantial policy of the world community in the field of higher education. 


\section{Acknowledgment}

This research was completed as part of the project "The Youth's Portrait" of the Future: Methodology of Investigating Representations" funded by the Russian Humanitarian Scientific Fund. Grant Number 15-03-00812a.

\section{References}

Adler, P. A. \& Adler, P. (1987). Membership roles in field research. Newbury Park, CA: Sage.

Babbie, E.R. (2008). The Practice of Social Research. Wadsworth: Thomson Learning Inc.

Becker, H.S. (1990). The Epistemology of Qualitative research. S.I.: Howard S. Becker.

Brent, J. (1998). Charles Sanders Peirce: A Life, 2nd edition. Bloomington and Indianapolis: Indiana University Press.

Communique of the World Conference on Higher Education (2009). UNESCO. Electronic resource. Paris, 2009. URL: http://www.unesco.org/en/wche2009/resources/conference-documents/

Creswell, J. W. (2003). Research design: Qualitative, quantitative, and mixed method approaches. Thousand Oaks. CA: Sage Publications.

Denzin, N.K., Lincoln, Y.S. (2011). The SAGE Handbook of qualitative research (4th ed.). Los Angeles: Sage Publications.

Firebaugh, G. (2008). Seven Rules for Social Research. Princeton University Press.

Franklin, M. I. (2012). Understanding Research: Coping with the Quantitative-Qualitative Divide. London/New York. Routledge

Gorshkov, M.K., \& Sheregi, F.E. (2010). Youth of Russia: sociological portrait. Moscow.

Gubrium, J.F., \& Holstein, J. A. (2009). Analyzing Narrative Reality. Thousand Oaks, CA: Sage.

Halliday, M.A.K. (1978). Language as social semiotic: The social interpretation of language and meaning. Maryland. University Park Press.

Hodge, R., \& Kress. G. (1988). Social Semiotics. Cambridge: Polity.

Inglehart, R., \& Welzel, C. (2005). Modernization, Cultural Change and Democracy: The Human Development Sequence. Cambridge University Press.

Lebedeva, N.M. (2009). Values as component in the characterization of the Russian national character and its impact on Russia's economic development. World of Psychology. 3, 58-68.

Maldonado-Maldonado, A., \& Verger, A. (2010). Politics, UNESCO, and Higher Education: A Case Study. International Higher Education, 58, 8-10.

Neuman, L.W. (2006). Social Research Methods: Qualitative and Quantitative Approaches, 6th edition, Allyn \& Bacon.

Ragin, C. (1994). Constructing Social Research: The Unity and Diversity of Method. Pine Forge Press.

Randviir, A. (2004). Mapping the World: Towards a Sociosemiotic Approach to Culture. Tartu: Tartu University Press. 